\title{
JCOM \\ Rethinking science communication in a changing landscape
}

\section{Frank Kupper, Carolina Moreno-Castro and Alessandra Fornetti}

\begin{abstract}
Science communication continues to grow, develop and change, as a practice and field of research. The boundaries between science and the rest of society are blurring. Digitalization transforms the public sphere. This JCOM special issue aims to rethink science communication in light of the changing science communication landscape. How to characterize the emerging science communication ecosystem in relation to the introduction of new media and actors involved? What new practices are emerging? How is the quality of science communication maintained or improved? We present a selection of papers that provide different perspectives on these questions and challenges.
\end{abstract}

Keywords

DOI

Public engagement with science and technology; Science and media; Science communication: theory and models

https://doi.org/10.22323/2.20030501

Submitted: 9th April 2021

Accepted: 12th April 2021

Published: 10th May 2021

Introduction

Science communication continues to grow, develop and change, as a practice and professional career path, and as an interdisciplinary field of research. While science communication may be more important than ever, it is also more challenging. The current pandemic, the climate crisis and the introduction of new technologies such as AI, challenge established relationships between science, media, publics and politics. In the past decades, the discussion about these issues has moved out of the protected environment of expert communities into the public arena. The boundaries between science and society have become porous and are increasingly crossed in both directions. A process that has only been intensified by the massive digitalization of the public sphere. Both developments have increased the diversity of actors engaged in science and science-related issues, including actors that have so far not been taken into account such as civil society organizations or citizens themselves. This has opened new opportunities for dialogue and collaboration but also increased polarization and controversy, as science-related issues are openly disputed across public fora. Is science communication part of the solution to maintain or rebuild trustworthy science-society relationships? At least, it is 
increasingly included in institutional discourses. This was for example the case with the first ever launched call by the EU Commission (2019) entitled: 'Taking stock and re-examining the role of science communication.' It entirely focused on the role played by science communication with and for society over the last decades, with the goal of opening up a multidisciplinary, international and cross-cultural reflection on its state-of-the-art as well as its challenges and opportunities.

This JCOM special issue originates from three EU funded projects - QUEST, RETHINK, CONCISE - which answered that call. We agree it is time to rethink science communication. How is the science communication ecosystem developing in response to the above mentioned changes in the science-society relationship? What is changing due to the introduction of new media and publics? What new practices are emerging? How is the quality of science communication maintained or improved?

We received a total of 45 manuscripts from 23 countries, with the majority of women as corresponding authors, as in the tables 1 and 2.

Table 1. Manuscripts received for the RETHINK special issue.

\begin{tabular}{|l|c|c|c|}
\hline $\begin{array}{l}\text { Country } \\
\text { (corresponding author) }\end{array}$ & $\begin{array}{c}\text { Accepted } \\
\text { papers }\end{array}$ & $\begin{array}{c}\text { Rejected } \\
\text { papers }\end{array}$ & $\begin{array}{c}\text { Total } \\
\text { result }\end{array}$ \\
\hline Afghanistan & 1 & 1 & $\mathbf{1}$ \\
\hline Australia & 1 & & $\mathbf{1}$ \\
\hline Austria & & 1 & $\mathbf{1}$ \\
\hline Bangladesh & & 1 & $\mathbf{1}$ \\
\hline Belgium & & 2 & $\mathbf{2}$ \\
\hline Brazil & & 1 & $\mathbf{1}$ \\
\hline Chile & & 1 & $\mathbf{1}$ \\
\hline Denmark & 1 & & $\mathbf{1}$ \\
\hline Estonia & 1 & & $\mathbf{1}$ \\
\hline Finland & 3 & 2 & $\mathbf{5}$ \\
\hline Germany & & 2 & $\mathbf{2}$ \\
\hline India & 1 & & $\mathbf{1}$ \\
\hline Ireland & & 1 & $\mathbf{1}$ \\
\hline Israel & 3 & 3 & $\mathbf{6}$ \\
\hline Italy & & 1 & $\mathbf{1}$ \\
\hline Mexico & 1 & & $\mathbf{1}$ \\
\hline Netherlands & 2 & 4 & $\mathbf{6}$ \\
\hline Portugal & & 3 & $\mathbf{3}$ \\
\hline Spain & & 1 & $\mathbf{1}$ \\
\hline Thailand & $\mathbf{1 5}$ & $\mathbf{3 0}$ & $\mathbf{3}$ \\
\hline $\begin{array}{l}\text { United Kingdom of Great } \\
\text { Britain and Northern Ireland }\end{array}$ & & & $\mathbf{4 5}$ \\
\hline United States of America & & & \\
\hline Total Result & & & \\
\hline
\end{tabular}


Table 2. Gender of the corresponding authors.

\begin{tabular}{|l|c|c|c|}
\hline $\begin{array}{l}\text { Gender } \\
\text { (corresponding authors) }\end{array}$ & $\begin{array}{c}\text { Accepted } \\
\text { papers }\end{array}$ & $\begin{array}{c}\text { Rejected } \\
\text { papers }\end{array}$ & $\begin{array}{c}\text { Total } \\
\text { Result }\end{array}$ \\
\hline Males & 3 & 13 & $\mathbf{1 6}$ \\
\hline Females & 12 & 17 & $\mathbf{2 9}$ \\
\hline Total Result & $\mathbf{1 5}$ & $\mathbf{3 0}$ & $\mathbf{4 5}$ \\
\hline
\end{tabular}

The changing landscape of science communication

Digital ecologies
One of the starting points for this special issue was the observation that the science communication landscape is undergoing deep and fundamental changes. First, the boundaries between science and society are blurring: the network of connections between science and society is becoming ever more complex, fragmented, heterogeneous and context-specific. Second, digitalisation of the public sphere has transformed the science communication landscape even more. It has fundamentally changed how scientists and a variety of publics interact and communicate. For both science communication research and practice, this raises the question what these changes mean for the interaction and communication processes that take place, the actors involved, their roles and relationships. We therefore start this special issue with a snapshot of European science communication provided by Sarah Davies et al. [2021]. Building on different studies within the QUEST project, she explores contemporary practices, priorities and struggles. Davies portrays a disparate and fragmented landscape, comprising diverse epistemologies, practices and standards. A landscape that is currently in transition, mainly due to digitalization - and pluralisation - of the media.

The next three papers explore the implications of the digitalization of the media landscape in more depth and detail. Emma Weitkamp et al. [2021] provides an overview of the emerging digital ecology of science communication. Comparing three European countries studied in the RETHINK project, she shows that even though the range of actors producing science-related content is considerably broadened, traditional science media and journalists remain quite visible across different platforms. While scientists themselves do contribute to public communication, many of them are not highly visible. In another RETHINK study, Tessa Roedema and colleagues [2021] analyse the online engagement practices of scientists. They examine how scientists perceive their role and interactions in the digital public sphere and make the case for a more reflective practice to deal with the struggles and challenges encountered online. Kaisu Koivumaki et al. [2021] highlights another implication of digitalisation. The increased opportunities for scientists to interact directly with different publics come with certain challenges, for example with respect to the relationship with communication professionals and the distribution of roles and responsibilities for science communication in research organizations. In this qualitative interview study, Koivumaki describes several ambiguities and uncertainties that challenge the uptake of new communication roles. 
The study of science communication in the digital era

What about quality?

What do citizens say?
Changes in the landscape of science communication, intensified by the digitalisation of the public sphere, also have implications for how we understand and study science communication. We have included several papers that suggest new directions for the study of science communication. Based on RETHINK's Delphi study with international science communication scholars, Birte Fähnrich [2021] advocates a broad conceptual approach, encompassing all forms of communication about science-related topics. This would allow for the consideration of a broader variety of actors, roles, motives and contexts. Also Massimiano Bucchi and Brian Trench [2021] call for embracing the richness and diversity of science communication. Arguing against a too narrow definition and standardization of science communication, they construct a view of science communication as a collection of social conversations around science. Finally, Monica Taddicken and Nicole Krämer [2021], based on an analysis of changing communication practices online, outline three theoretical strands for future research: the affordances of technological structures that shape communication practices, the new order of knowledge along with the increasing diversity of actors involved and the role of trust and rationality in social issues around science.

Digitalization, the spread of misinformation, and the increasing variety of media, sources and actors involved, all raise questions about the quality of the communication that is produced. The need to improve quality is certainly not new in the science communication discourse. However, the increasing diversity of actors involved in science communication practices also extends the range of actors that are - or should be - involved in the discussion of quality. The QUEST project therefore developed a co-design process that directly engaged key stakeholders in identifying both challenges and solutions around the quality of communication about science. In his contribution to the special issue, Arko Olesk et al. [2021] proposes the co-constructed quality framework, consisting of 12 indicators arranged into three dimensions. With this framework science communicators and their practices could be supported cross-sectorally. Ilda Mannino and colleagues [2021] present the identified barriers to the quality of science communication. The paper highlights how quality depends on all stakeholders involved and requires changes at policy and decision-making level. Eventually, Mannino proposes a series of tools and incentives designed for science communicators, particularly in the areas of journalism, social media and museums, to overcome barriers and improve the quality of science communication.

The emerging science communication landscape deeply changes the way citizens engage with science and science information. While the publics of science communication have long been approached as passive receivers of information their more active role in the digital landscape asks for better insight into the public perspective. Public communication is more complicated than the old knowledge deficit model suggests. The CONCISE project therefore held citizen consultations in five European countries. How do different publics navigate the emerging science communication landscape and engage with science? The consultations collected the ideas and opinions of more than 500 European citizens about different issues in science communication. Sonia Brondi and colleagues [2021] identify different dimensions of trust in science and science communication from the perspectives of 
citizens. Moreover, they report how information sources and channels are related to these dimensions of trust. Giuseppe Pellegrini and colleagues [2021] use the specific context of climate change communication to explore the preferences of citizens for public communication and engagement. Ana Delicado and colleagues [2021], finally, further explores the finding of the Portuguese consultation that citizens prefer unmediated communication above mediated communication.

New practices of science communication

Conclusion and outlook

\section{References}

The changes in the communication landscape also lead to new science communication practices, often in response to the increasing variety of actors involved and the call for more interactive and dialogical communication. We conclude the special issue with three papers that explore these new practices. Sara Anjos and colleagues [2021] emphasize the contribution that communities of practice can make to public engagement of science by analysing a community of practice in astronomy communication. Linda Orthia and colleagues [2021] discuss three different approaches to community engagement to articulate the basic principles of community-oriented science communication. Katherin Wagenknecht and colleagues [2021], finally, review how the emerging practice of citizen science is related to and can enhance science communication.

The papers included in this issue show a field that is still very much in flux. We were impressed by the variety of actors that were portrayed, such as scientists and journalists, but also communication professionals, societal stakeholders, citizens. In that sense, the included papers reflect the blurring of boundaries and the disruption of conventional processes of interaction and communication between science and society. We also note that the discussions about the emerging landscape and the changing practices of science communication are still at the start.

Rethinking science communication requires a more reflexive mode of science communication that bridges research and practice, incorporates the perspectives of stakeholders and citizens and nurtures collaboration and dialogue across disciplines and divides.

Anjos, S., Russo, P. and Carvalho, A. (2021). 'Communicating Astronomy with the Public: Perspectives of an international community of practice'. JCOM 20 (03), A11. https://doi.org/10.22323/2.20030211.

Brondi, S., Pellegrini, G., Guráň, P., Fero, M. and Rubin, A. (2021). 'Paths of Trust in Science: How citizens use sources and channels of communication to get science information and science knowledge'. JCOM 20 (03), A08. https://doi.org/10.22323/2.20030208.

Bucchi, M. and Trench, B. (2021). 'Science communication as the social conversation around science'. JCOM 20 (03), Y01. https: //doi.org/10.22323/2.20030401.

Davies, S. R., Franks, S., Roche, J., Schmidt, A. L., Wells, R. and F., Z. (2021). 'The Landscape of European Science Communication'. JCOM 20 (03), A01. https://doi.org/10.22323/2.20030201.

Delicado, A., Rowland, J. and Estevens, J. (2021). 'Bringing back the debate on mediated and unmediated science communication: the public's perspective'. JCOM 20 (03), A10. https://doi .org/10.22323/2.20030210. 
Dziminska, M., Mendoza-Poudereux, I., Pellegrini, G. and J., R. (2021). 'Climate change and public perception. Citizens' proposals for better communication and involvement'. JCOM 20 (03), A09. https://doi .org/10.22323/2. 20030209.

Fähnrich, B. (2021). 'Conceptualizing science communication in flux - a framework for analyzing science communication in a digital media environment'. JCOM 20 (03), Y02. https : //doi . org/10 .22323/2. 20030402.

Koivumäki, K., Koivumäki, T. and Karvonen, E. (2021). 'Challenges in the collaboration between researchers and in-house communication professionals in the digital media landscape'. JCOM 20 (03), A04. https://doi.org/10.22323/2.20030204.

Mannino, I., Bell, L., Costa, E., Di Rosa, M., Fornetti, A., Franks, S., Iasillo, C., Maiden, N., Olesk, A., Pasotti, J., Renser, B., Roche, J., Schofield, B., Villa, R. and F., Z. (2021). 'Supporting Quality in Science Communication: Insights from the QUEST Project'. JCOM 20 (03), A07. https://doi.org/10.22323/2.20030207.

Olesk, A., Renser, B., L., B., Fornetti, A., Franks, S., Mannino, I., Roche, J., Schmidt, A. L., Schofield, B., Villa, R. and Zollo, F. (2021). 'Quality Indicators for Science Communication: Results from a Collaborative Concept Mapping Exercise'. JCOM 20 (03), A06. https: //doi .org/10.22323/2.20030206.

Orthia, L. A., McKinnon, M., Viana, J. N. and Walker, G. J. (2021). 'Reorienting science communication towards communities'. JCOM 20 (03), A12. https://doi.org/10.22323/2.20030212.

Roedema, T. F. L., Broerse, J. E. W. and Kupper, F. (2021). "“Who is going to believe me, if I say 'I'm a researcher?"' - Scientists' role repertoires in online public engagement'. JCOM 20 (03), A03. https://doi .org/10.22323/2.20030203.

Taddicken, M. and Krämer, N. (2021). 'Public Online Engagement with Science Information: On the Road to a Theoretical Framework and a Future Research Agenda'. JCOM 20 (03), A05. https: //doi.org/10.22323/2. 20030205.

Wagenknecht, K., Woods, T., Nold, C., Rüfenacht, S., Voigt-Heucke, S., Caplan, A., Hecker, S. and Vohland, K. (2021). 'A question of dialogue? Reflections on how citizen science can enhance communication between science and society'. JCOM 20 (03), A13. https: //doi .org/10.22323/2.20030213.

Weitkamp, E., Milani, E., Ridgway, A. and Wilkinson, C. (2021). 'Exploring the digital media ecology: Insights from a study of healthy diets and climate change communication on digital and social media'. JCOM 20 (03), A02. https://doi.org/10.22323/2.20030202.

Authors

Dr. Frank Kupper is Associate Professor in Science Communication \& Public Engagement at the Vrije Universiteit Amsterdam. He has an interdisciplinary background in science and philosophy and is an established scholar in public engagement research. His research particularly focuses on openness, reflexivity, dialogue and transformative learning in science-society interaction and communication processes. He participated as a research partner in several national and EU-funded projects on public engagement, ethical deliberation and RRI. He currently leads the H2020 consortium RETHINK. E-mail: f.kupper@vu.nl.

Prof. Dr. Carolina Moreno-Castro is a Full Professor of Science Communication and a member of the Research Institute on Social Welfare Policy (POLIBIENESTAR), at the University of Valencia. During the last decade, she was leading a research team, Scienceflows, where she was coordinating several research projects about risk communication and science communication. she has published over 100 works 
about the representativeness, social treatment, and perception of health, science, technology and environment on media and social networks.

E-mail: carolina.moreno@uv.es.

Alessandra Fornetti is Executive Director of the TEN Program on Sustainability, Venice International University (VIU), Italy. With a humanities background, she has been working for almost two decades in the field of environmental sciences developing international projects on education, communication and dissemination, to peers and the wide public, with experiences in China, East Europe and Central Asia. As VIU, she is coordinator of H2020 QUEST on science communication and partner in MUHAI on Artificial Intelligence.

E-mail: alessandra.fornetti@univiu.org.

How to cite

Kupper, F., Moreno-Castro, C. and Fornetti, A. (2021). 'Rethinking science communication in a changing landscape'. JCOM 20 (03), E.

https://doi.org/10.22323/2.20030501. 